\title{
Alleviating Aspirin-Induced Gastric Injury by Binding Aspirin to $\beta$-Lactoglobulin
}

\author{
Jin Chen $\mathbb{D}^{\prime, *}$, Min Gong ${ }^{1, *}$, Zhuo Huang', Fang Wang ${ }^{2}$, Yajing Wang ${ }^{3}$, Zuquan Hu $\mathbb{D}^{\prime}$, Zhu Zeng', \\ Yun Wang ${ }^{2}$
}

'Key Laboratory of Biology and Medical Engineering/Immune Cells and Antibody Engineering Research Center of Guizhou Province, School of Biology and Engineering, Guizhou Medical University, Guiyang, 550025, People's Republic of China; ${ }^{2}$ Key Laboratory of Infectious Immune and Antibody Engineering of Guizhou Province, School of Basic Medical Sciences, Guizhou Medical University, Guiyang, 550025, People's Republic of China; ${ }^{3}$ The Affiliated Stomatological Hospital of Guizhou Medical University, Guizhou Medical University, Guiyang, 550025, People's Republic of China

*These authors contributed equally to this work

Correspondence: Zhu Zeng, Key Laboratory of Biology and Medical Engineering/Immune Cells and Antibody Engineering Research Center of Guizhou Province, School of Biology and Engineering, Guizhou Medical University, Guiyang, 550025, People’s Republic of China, Email zengzhu@gmc.edu.cn; Yun Wang, Key Laboratory of Infectious Immune and Antibody Engineering of Guizhou Province, School of Basic Medical Sciences, Guizhou Medical University, Guiyang, 550025, People's Republic of China, Tel/Fax +8685I-88I74044, Email wangyun@gmc.edu.cn

Purpose: Gastric injury is a major issue for long-term administration of aspirin. In this work, we tried to explore the possibility of using BLG to alleviate aspirin-induced gastric injury, because of excellent abilities of BLG in loading drug molecules.

Methods: Various spectroscopic techniques and molecular docking methods were applied to investigate the interaction mechanism between BLG and aspirin. Animal experiments were performed to figure out the effects of taking aspirin-BLG on the stomach.

Results: Our results demonstrate that aspirin could bind with BLG to form stable aspirin-BLG complex (the binding constant $K_{b}=$ $\left.2.051 \times 10^{3} \mathrm{M}^{-1}\right)$. The formation process is endothermic $(\Delta \mathrm{H}>0)$ and the main acting force is hydrophobic force. Our data also show that the aspirin-BLG complex is formed with a higher affinity in simulated gastric fluid and could remain stable for several hours, which might arise from its special binding mode under acidic condition and the resistance of BLG to gastric digestion. Furthermore, animal models (rats with aspirin-induced gastric damage) were built. The results of animal experiments reveal that the oral administration of aspirin-BLG could cause less damage to gastric tissue, and it also hardly triggers obvious inflammatory responses. Conclusion: This study would contribute to an in-depth understanding of the interaction mechanism between BLG and aspirin. It is reasonable to believe that using BLG to bind with aspirin would be a potential way to alleviate the aspirin-induced gastric injury.

Keywords: beta-lactoglobulin, aspirin, gastric injury, static quenching, molecular docking

\section{Introduction}

Aspirin, as a nonsteroidal anti-inflammatory drug, is originally used as antipyretic and analgesic agents. ${ }^{1}$ Since the antiplatelet activity of aspirin has been discovered, aspirin is considered to have great clinical application value in the treatment of cardiovascular diseases and anti-tumor, ${ }^{2-4}$ and also has potential clinical efficacy in the treatment of neurodegenerative diseases, sepsis and acute respiratory distress syndrome. ${ }^{2,5}$ For the long-term administration of aspirin, a major side effect is aspirin-induced gastric injury, which increases the risk of gastric ulcer and stomach bleeding. ${ }^{6,7}$ Alleviating the side effect of aspirin on gastric tissue has become an extremely hot and competitive research area. ${ }^{5,7-9}$ The mechanisms of aspirin-induced gastric injury are complex and can be roughly divided into two categories: ${ }^{3,7,8}$ the prostaglandin-dependent mechanism involving the suppressed prostaglandin production arising from the inhibition of cyclooxygenase by aspirin, and the non-prostaglandin-dependent mechanism involving the apoptosis of gastric epithelial cells caused by the accumulation of aspirin within cells. For either way, once the mucosal barrier has been broken, infiltrated immune cells would secrete a series of pro-inflammatory cytokines to trigger immune responses, resulting in 


\section{Graphical Abstract}

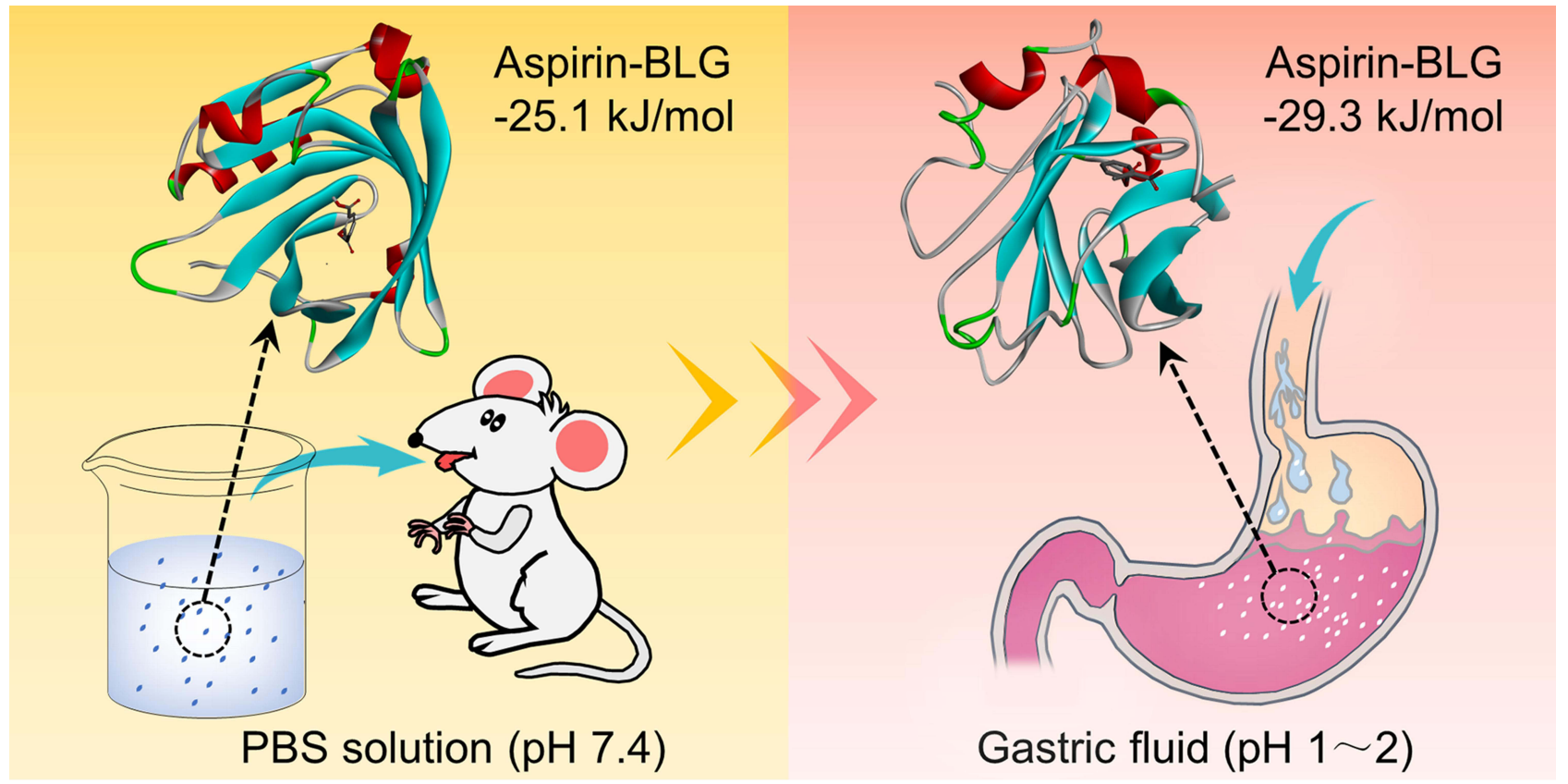

inflammation and exacerbated gastric mucosal damage.$^{8-10}$ These studies have indicated that reducing the direct irritation of aspirin to gastric mucosa is the key to alleviating aspirin-induced gastric injury.

Some strategies have been developed such as altering the route of administering aspirin (eg, inhalation and transdermal delivery $)^{11,12}$ or co-administration of aspirin with other drugs. ${ }^{10,13,14}$ However, oral administration is still the most common way of using aspirin. Meanwhile, co-administration usually has a limited therapeutic range and may bring new side effects. Recently, using carriers as oral delivery systems has received significant scientific and technological attention, ${ }^{15-17}$ and some carriers have been designed for aspirin, such as poly (lactic-co-glycolic acid)polyethylene glycol nanoparticle, ${ }^{5}$ nano-hydroxyapatite/poly(styrene-divinylbenzene) porous microsphere, ${ }^{18}$ natural or chitosan modified halloysite nanotubes, ${ }^{19,20}$ and some natural proteins (eg, human or bovine serum albumin). ${ }^{21,22}$ Many researchers have pointed out that the ideal carriers should have an appropriate affinity to aspirin and a good resistance to gastric digestion. ${ }^{18-20}$ In addition, the carriers should also be low-cost (to facilitate mass production), biocompatible and biodegradable (to ensure biosafety).

Bovine $\beta$-lactoglobulin (BLG) is a globular protein from the milk (accounting for $\sim 12 \mathrm{wt} \%$ of total milk proteins) and widely utilized in the food industry due to its easy purification, high nutritional value and multifunctional properties. ${ }^{23}$ Native BLG contains 162 amino acid residues with a molecular mass of $18.3 \mathrm{kDa}$ and consists of nine antiparallel $\beta$ strands (strands A-I) and one triple turn alpha-helix ( $\alpha$-helix). ${ }^{23,24}$ Eight $\beta$-strands (A-H) fold up into a flattened betabarrel ( $\beta$-barrel) and the $\alpha$-helix is located on the outer surface of $\beta$-barrel, offering three main regions for ligand binding: the central hydrophobic cavity of $\beta$-barrel, the external surface near the bottom of $\beta$-barrel, and the groove between the $\alpha$ helix and the $\beta$-barrel. ${ }^{24-26}$ The protein structure of BLG is $\mathrm{pH}$-sensitive, a typical representative of which is the reversible opening-closure of EF loop. EF loop acts as a gate to control the accessibility of the central hydrophobic cavity of $\beta$-barrel, which prevents ligand binding below $\mathrm{pH} 7.1$ but enables binding at higher $\mathrm{pH}$ values. ${ }^{24,25,27}$ Recent theoretical and experimental studies have shown that BLG, as a member of the lipocalin superfamily, exhibits excellent abilities to bind various hydrophobic and amphiphilic agents or drug, such as porphyrins, ${ }^{27}$ curcumin/gemcitabine, ${ }^{28}$ platinum complex, ${ }^{29}$ resveratrol, ${ }^{30}$ biguanides, ${ }^{31}$ curcuminoids, ${ }^{32}$ and quercetin. ${ }^{33}$ Therefore, BLG has drawn a lot of 
attention in the fields of drug loading and transportation. ${ }^{34-36}$ In addition, some reports also show that BLG has a peculiar resistance to gastric digestion. ${ }^{24,35}$ Hence, BLG could be employed as a carrier (or part of a carrier) for binding aspirin to alleviate the aspirin-induced gastric injury. However, the interaction mechanism between BLG and aspirin under different environmental conditions, especially the special binding sites and corresponding affinities, remains to be further explored, which is crucial in drug carrier research but rarely receives attention.

In this work, we sought to explore the possibility of using BLG as a carrier (or part of a carrier) for aspirin. To this end, various spectroscopic techniques and molecular docking methods were applied to figure out the interactions of BLG with aspirin under different conditions, including PBS solution and simulated gastric fluid. Furthermore, to evaluate the effects of taking aspirin-BLG on the stomach, animal models (rats with aspirin-induced gastric damage) were built. It is reasonable to believe that our findings would provide new insights into the formation mechanism of aspirin-BLG complex and offer a potential way to alleviate the aspirin-induced gastric injury.

\section{Materials and Methods}

\section{Chemicals}

BLG (from bovine milk, purity > 90\%), 8-anilino-1-naphthalenesulfonate (ANS) and aspirin were purchased from Sigma-Aldrich (USA). Pepsin was purchased from Solarbio (China). Other reagents and materials were analytical grade and used without further purification.

\section{Solution Preparation}

BLG powder was dissolved into sterile phosphate buffered saline (PBS) solution to prepare $1 \mathrm{mM}$ BLG stock solution. The concentration of BLG stock solution was determined spectrophotometrically at $278 \mathrm{~nm}$ with a molar extinction coefficient of 17,600 $\mathrm{M}^{-1} \mathrm{~cm}^{-1}$. ${ }^{37}$ Aspirin was initially dissolved in ethanol to prepare $1 \mathrm{M}$ aspirin solution in ethanol, and then diluted with PBS solution to yield $20 \mathrm{mM}$ aspirin stock solution. The simulated gastric fluid was prepared by adding $0.2 \mathrm{~g} \mathrm{NaCl}$ and $0.32 \mathrm{~g}$ pepsin into $100 \mathrm{~mL}$ ultrapure water, and its $\mathrm{pH}$ was adjusted to $1.2 \mathrm{using} 1 \mathrm{M} \mathrm{HCl}$. All solutions were prepared under normal indoor lighting and at room temperature.

\section{Preparation of Aspirin-BLG Complex}

Aspirin-BLG stock solutions with various ratios of aspirin to BLG were prepared by adding appropriate amounts of BLG stock solution into PBS solution, followed by adding appropriate amounts of aspirin stock solution. The concentrations of BLG and aspirin were $25 \mu \mathrm{M}$ and $0-10 \mathrm{mM}$, respectively. For the preparation of aspirin-BLG complex in PBS solution, $1 \mathrm{~mL}$ of aspirin-BLG stock solution was added into $4 \mathrm{~mL}$ of PBS solution. The final concentrations of BLG and aspirin were 5 and $0-2000 \mu \mathrm{M}$, respectively. The system was adjusted to $\mathrm{pH} 7.4$, followed by incubating at $27^{\circ} \mathrm{C}$ or $37^{\circ} \mathrm{C}$. For the preparation of aspirin-BLG complex in simulated gastric fluid, $1 \mathrm{~mL}$ of aspirin-BLG solution was added into $4 \mathrm{~mL}$ of simulated gastric fluid. The final concentrations of BLG and aspirin were also 5 and $0-2000 \mu \mathrm{M}$, respectively. The system was adjusted to $\mathrm{pH} 1.2$, followed by incubating at $37^{\circ} \mathrm{C}$. All of the above aspirin-BLG complexes were freshly prepared just before use.

\section{Characterization}

Fluorescence studies were performed using a fluorescence spectrophotometer (Hitachi F-4600, Japan). UV-vis absorption spectra were measured using a UV-vis spectrophotometer (Shimadzu, UV2600, Japan). Circular dichroism (CD) spectra were achieved using a Chirascan qCD spectrometer (Applied Photophysics, UK), the obtained results were analyzed using CDNN software.

\section{Fluorescence Quenching Study}

The excitation wavelength was set to $295 \mathrm{~nm}$, and the emission wavelength was recorded from 290 to $500 \mathrm{~nm}$. The bandwidths of excitation and emission monochromator were set to $5 \mathrm{~nm}$. All the recorded fluorescence intensities were corrected for the inner-filter effect. ${ }^{38}$ The modified Stern-Volmer equations were applied to calculate the fluorescence 
quenching parameters. ${ }^{27,39,40}$ For the Eq. 1 , the $[C]$ is the concentration of quencher (ie, aspirin), the $F_{0}$ and $F$ are the maximum fluorescence intensities in the absence and presence of aspirin, and the $K_{S V}$ is the Stern-Volmer quenching constant. For the Eq. 2, the $K_{q}$ is the biomolecular quenching rate constant and the $\tau_{0}$ is the fluorescence average lifetime of the fluorophore.

$$
\begin{gathered}
\frac{\mathrm{F}_{0}}{\mathrm{~F}_{0}-\mathrm{F}}=\frac{1}{\mathrm{~K}_{\mathrm{SV}} \mathrm{f}_{\mathrm{a}}} \frac{1}{[\mathrm{C}]}+\frac{1}{\mathrm{f}_{\mathrm{a}}} \\
\mathrm{K}_{\mathrm{SV}}=\mathrm{K}_{\mathrm{q}} \tau_{0}
\end{gathered}
$$

\section{Fluorescence Resonance Energy Transfer (FRET) Study}

FRET is a useful method to estimate the distance $\left(r_{0}\right)$ between the donor (the fluorophore of protein) and the acceptor (the ligand molecule) ${ }^{40,41}$ The value of $r_{0}$ can be calculated following Eq. 3-5. The $E$ is the efficiency of energy transfer between the donor and the acceptor, the $R_{0}$ is the critical distance when the transfer efficiency is $50 \%$, the $K^{2}$ is the orientation factor, the $N$ is the refractive index, and the $\varphi$ is the fluorescence quantum yield. The $J$ is the spectral overlap integral between the emission spectrum of the donor and the absorption spectrum of the acceptor. The $F(\lambda)$ represents the fluorescence intensity of the donor, and the $\varepsilon(\lambda)$ represents the molar extinction coefficient of the acceptor.

$$
\begin{gathered}
\mathrm{E}=1-\frac{\mathrm{F}}{\mathrm{F}_{0}}=\frac{\mathrm{R}_{0}^{6}}{\mathrm{R}_{0}^{6}+\mathrm{r}_{0}^{6}} \\
\mathrm{R}_{0}^{6}=8.79 \times 10^{-25} \mathrm{~K}^{2} \mathrm{~N}^{-4} \varphi \mathrm{J} \\
J=\frac{\sum \mathrm{F}(\lambda) \varepsilon(\lambda) \lambda^{4} \Delta \lambda}{\sum \mathrm{F}(\lambda) \Delta \lambda}
\end{gathered}
$$

\section{Thermodynamic Analysis}

The thermodynamic parameters of the ligand-protein complex formation were calculated using the Eq. 6 and $7 .^{42,43}$ The $K_{b}$ is the binding constant at corresponding temperature, and the $n$ is the average number of binding sites. The $T$ is the thermodynamic temperature, and the $R$ is the gas constant.

$$
\begin{gathered}
\log \left[\frac{F_{0}-F}{F}\right]=\log K_{b}+n \log [C] \\
\Delta G=-R T \ln K_{b}=\Delta H-\Delta S
\end{gathered}
$$

\section{Molecular Docking Study}

The protein structures of $\mathrm{BLG}$ at $\mathrm{pH}=7.4$ (ID: 2GJ5) and at $\mathrm{pH}=2.0$ (ID: 1CJ5) were obtained from the RCSB Protein Data Bank (http://www.rcsb.org/pdb). The 2GJ5 file was obtained from X-ray diffraction data, and its resolution and R-value are $2.40 \AA$ and 0.241 . The 1CJ5 file was obtained from solution NMR data, and its conformers calculated and conformers submitted are 200 and 10. The molecular structure of aspirin was modeled using ChemDraw Professional 19 software, and optimized to the minimized energy states using the "Minimize Energy" function of the software. AutoDock Vina software was utilized to perform molecular docking analyses. Before docking analysis, the BLG molecules were dehydrated and hydrotreated using AutoDockTools. In the docking process, the $\mathrm{X}, \mathrm{Y}$, and $\mathrm{Z}$ axes was performed to find the active sites of the ligands related to BLG, and the ligand was allowed to rotate freely. For aspirin-BLG complex under the condition of $\mathrm{pH} 7.4$, three binding sites were chosen according to previous researches, ${ }^{23-25}$ in which the size of grid box used in docking process was $20 \times 20 \times 20 \AA$ with a grid point spacing of $1 \AA$. For the aspirin-BLG complex under the condition of $\mathrm{pH} 2.0$, the molecular docking was performed via blind docking way, in which the size of grid box used in 
docking process was $40 \times 40 \times 40 \AA$ with a grid point spacing of $1 \AA .200$ docking runs were performed for each site. The obtained results were analyzed using Discovery Studio 2020 software.

\section{Electrophoresis Analysis}

The $100 \mu \mathrm{M}$ BLG solution was prepared by adding an appropriate amount of BLG stock solution in simulated gastric fluid, and was incubated in a water bath at $37^{\circ} \mathrm{C}$ for $0.5 \mathrm{~h}, 1 \mathrm{~h}, 2 \mathrm{~h}, 3 \mathrm{~h}$ respectively. Then, $8 \mu \mathrm{L}$ solutions of each sample were mixed with loading buffer (Solarbio) and heated at $100{ }^{\circ} \mathrm{C}$ for $5 \mathrm{~min}$. The SDS-polyacrylamide gels were prepared using SDS-PAGE gel kit (Solarbio, China), and the stacking gel and separation gel were 5\% and 15\% acrylamide, respectively. After electrophoresis separations, coomassie blue R250 was used to stain protein bands. After decolorization, the gel was scanned using a Gel Doc XR+ (Bio-Rad, USA) and the gray values of protein bands were analyzed using Image $\mathrm{J}$ software.

\section{Animal Study}

All animal procedures were approved by the Institutional Animal Care and Use Committee at Guizhou medical university (permit number: 2100285). All animals received humane care according to the "Guide for the Care and Use of Laboratory Animals: Eighth Edition, 2011, The National Academies Press". A total of 15 Wistar rats were purchased from the Changsha Tianqin Biotechnology Co., Ltd. (China). The aspirin solution with a concentration of $3 \mathrm{mg} / \mathrm{mL}$ was prepared by adding an appropriate amount of aspirin stock solution in PBS solution, the system was adjusted to $\mathrm{pH}$ 7.4. The aspirin-BLG complex solution was prepared by adding appropriate amounts of aspirin stock solution and BLG powder in PBS solution, the system was also adjusted to $\mathrm{pH}$ 7.4. The final concentration of aspirin was $3 \mathrm{mg} / \mathrm{mL}$ and the mole ratio of aspirin to BLG was 1:1. All of the above solutions were freshly prepared just before use. The animals were housed at normal temperature $\left(\sim 22^{\circ} \mathrm{C}\right)$ in a $12 \mathrm{~h} \mathrm{light} / \mathrm{dark}$ cycle, and had access to food and water ad libitum. After been kept 1 week for adaptation, the rats (weighing $\sim 90 \mathrm{~g}$ ) were randomly divided into three equal groups, and fed with a single dose of the different drug solutions everyday $(10 \mathrm{~mL}$ per kilogram body weight, orally). For the first group, the rats were given the PBS solution and labeled as the PBS group. For the second group, the rats were given the aspirin solution and labeled as the aspirin group. For the third group, the rats were given the aspirinBLG complex solution and labeled as the aspirin-BLG group. All rats were sacrificed after 14 days of continuous treatment, and their gastric tissues were isolated, sectioned at $6 \mu \mathrm{m}$ and stained with hematoxylin-eosin (H\&E) using standard protocols.

\section{Quantitative Real-Time Reverse Transcription-PCR (qRT-PCR)}

Total RNA samples from gastric tissues were extracted using TRIzol (Invitrogen), and were reverse-transcribed using Fastking gDNA Dispelling RT Supermix (Tiangen Biotech. Biotechnology Co., Ltd., China). qRT-PCR analyses were performed using an Applied Biosystems StepOne Plus (Life Technologies) with TB Green Premix Ex TaqTM (TaKaRa, Japan) and corresponding primers. $\beta$-actin was used as an internal control to normalize mRNA expression levels. The primer sequences were listed in Table S1. The $2^{-\Delta \Delta C T}$ method was used to calculate the fold-change. Ct denotes the cycle number when the fluorescence signal of the amplification plot passed the fixed threshold.

\section{Statistical Analyses}

The results are presented as the mean \pm standard deviation (SD). The unpaired, two-sided Student's $t$-test was applied to all statistical analyses. ${ }^{*} \mathrm{P}<0.05$ is considered significant, ${ }^{* *} \mathrm{P}<0.01$ is considered highly significant, and N.S. means no significant difference.

\section{Results and Discussion}

Interaction of BLG with Aspirin in PBS Solution ( $\mathrm{pH}=7.4)$

Given that alkalescent or neutral drug solutions are easily acceptable for oral administration, the aspirin-BLG complex was first prepared in PBS solution ( $\mathrm{pH}=7.4)$. The results of fluorescence spectra (Figure 1A) show that, with excitation at 
$295 \mathrm{~nm}$, the fluorescence intensities at $408 \mathrm{~nm}$ gradually increase with increasing concentrations of aspirin, which should arise from the intrinsic fluorescence of aspirin (Figure S1). Meanwhile, the fluorescence intensities at $334 \mathrm{~nm}$ gradually decrease, manifesting that the interaction of aspirin with BLG would lead to the fluorescence quenching of tryptophan residues. ${ }^{44,45}$ It has to be pointed out that BLG mainly has two internal fluorophores: tryptophan residues (Trp-19 and 61) and tyrosine residues (Tyr-20, 42, 99 and 101). ${ }^{44,45}$ The results of synchronous fluorescence spectra (setting $\Delta \lambda=60 \mathrm{~nm}$ for Trp residues, and $\Delta \lambda=15 \mathrm{~nm}$ for Tyr residues ${ }^{46}$ show that the fluorescence intensities of Trp residues are stronger than those of Tyr residues, and the fluorescence quenching degree of Trp residues is much more obvious than that of Tyr residues (Figure S2). These results confirm that Trp residues are dominant in the total fluorescence emission and mainly responsible for the fluorescence quenching. It is worth noting that the intrinsic fluorescence of Trp residues is almost exclusively attributed to Trp-19 because it is located in an apolar environment. ${ }^{47}$

To shed light on the quenching mechanism, the modified Stern-Volmer equations (Eq. 1 and 2) were applied to calculate the fluorescence quenching parameters, ${ }^{39-41}$ in which the $\tau_{0}$ for the Trp residues of BLG at $\mathrm{pH}=7.4$ is to be 1.28 ns. ${ }^{44,48}$ As shown in Figure 1B, the dependences of $F_{0} /\left(F_{0}-F\right)$ on the value of the $[\mathrm{C}]^{-1}$ are linear. Then, the values of the $K_{S V}$ (Stern-Volmer quenching constant) and the corresponding $K_{q}$ (biomolecular quenching rate constant) could be calculated and the results are shown in Table 1. For the interaction of aspirin with BLG at $\mathrm{pH}=7.4$, the $K_{q}$ value is $1.001 \times 10^{12}$ at $27{ }^{\circ} \mathrm{C}$ and $0.964 \times 10^{12} \mathrm{M}^{-1} \mathrm{~s}^{-1}$ at $37{ }^{\circ} \mathrm{C}$, which are obviously greater than the maximal $K_{q}$ value of dynamic quenching constant $\left(2.0 \times 10^{10} \mathrm{M}^{-1} \mathrm{~s}^{-1}\right){ }^{26,39}$ The results of $K_{q}$ values suggest that the dominant mechanism of fluorescence quenching should be static rather than dynamic, which is similar to the binding of aspirin to human serum albumin and bovine serum albumin. ${ }^{21,22}$ Namely, the fluorescence quenching is mainly caused by the formation of aspirin-BLG complex instead of dynamic collision.

To evaluate the distance $\left(\mathrm{r}_{0}\right)$ between Trp-19 (major fluorescence contributor) of BLG and aspirin, FRET study was performed using the Eq. 3-5. ${ }^{40,41}$ In this case, the Trp-19 and the aspirin molecule are considered as the donor and acceptor respectively, the values of $K^{2}, N$ and $\varphi$ are set to $2 / 3,1.336$ and 0.12 , according to previous reports. ${ }^{40,49}$ Figure 1C displays the fluorescence emission spectrum of BLG and the UV-vis absorption spectrum of aspirin, then the $J$ is calculated by integration of the overlapping spectra in wavelength of $290-440 \mathrm{~nm}$ and its value is approximately $7.53 \times 10^{-18} \mathrm{~cm}^{3} \mathrm{M}^{-1}$. The calculated values of $R_{0}$ and $r_{0}$ are $0.74 \mathrm{~nm}$ and $1.05 \mathrm{~nm}$, respectively. According to Föster theory, the condition of non-radioactive energy transfer is $0.5 R_{0}<r_{0}<1.5 R_{0}$, and the $R_{0}<r_{0}<8 \mathrm{~nm}$ is strong evidence for static quenching. ${ }^{50,51}$ Therefore, the calculated $r_{0}$ and $R_{0}$ values reveal the occurrence of resonance energy transfer and suggest that static quenching is dominant in the quenching process, which is consistent with the hypothesis mentioned in the above section.

To further analyze the details of aspirin-BLG interaction, CD studies were applied to characterize the secondary structure of BLG in the absence and presence of aspirin (Figure 1D). The detailed contents of secondary structure elements were calculated and listed in Table S2. It can be seen that the proportions of the $\beta$-sheet and $\beta$-turn are decreased but the proportions of the $\alpha$-helix and random coil are increased, meaning a few conformational changes in the structure of BLG. Moreover, the accessible hydrophobic areas of BLG after its interaction with aspirin were also studied using ANS. ANS is a probe (excitation wavelength of $380 \mathrm{~nm}$ ) and mainly bind two hydrophobic areas of BLG: an internal site, located in the hydrophobic core, and an external site, near a hydrophobic patch on the external surface. ${ }^{39}$ The accessibilities of these hydrophobic areas were evaluated by measuring the emission fluorescence changes of ANS in the wavelength of 400-600 nm. As shown in Figure 1E, with the increased the ratio of aspirin, the ANS fluorescence intensity of each group gradually decreases and shows an evident red shift in the emission maxima. It implies that aspirin can compete with ANS for these hydrophobic areas, which not only reduces the accessibility of the original hydrophobic areas for binding ANS, but also increases the polarity of these areas. ${ }^{39,40}$ The results of CD studies and ANS binding analysis further confirm that the complex formation is the outcome of the interaction between BLG and aspirin.

\section{Formation Mechanism of Aspirin-BLG Complex in PBS Solution ( $\mathrm{pH}=7.4)$}

According to previous reports, in case of static quenching models, the binding parameters of the ligand-protein complex formation could be calculated using the Eq. $6 .{ }^{42,43}$ As shown in Figure $2 \mathrm{~A}$, the dependences of $\log \left[\left(F_{0}-F\right) / F\right]$ on the $\log [\mathrm{C}]$ are linear. Thus, the detailed values of $K_{b}$ and $n$ at different temperatures are calculated and listed in Table 2. It can 

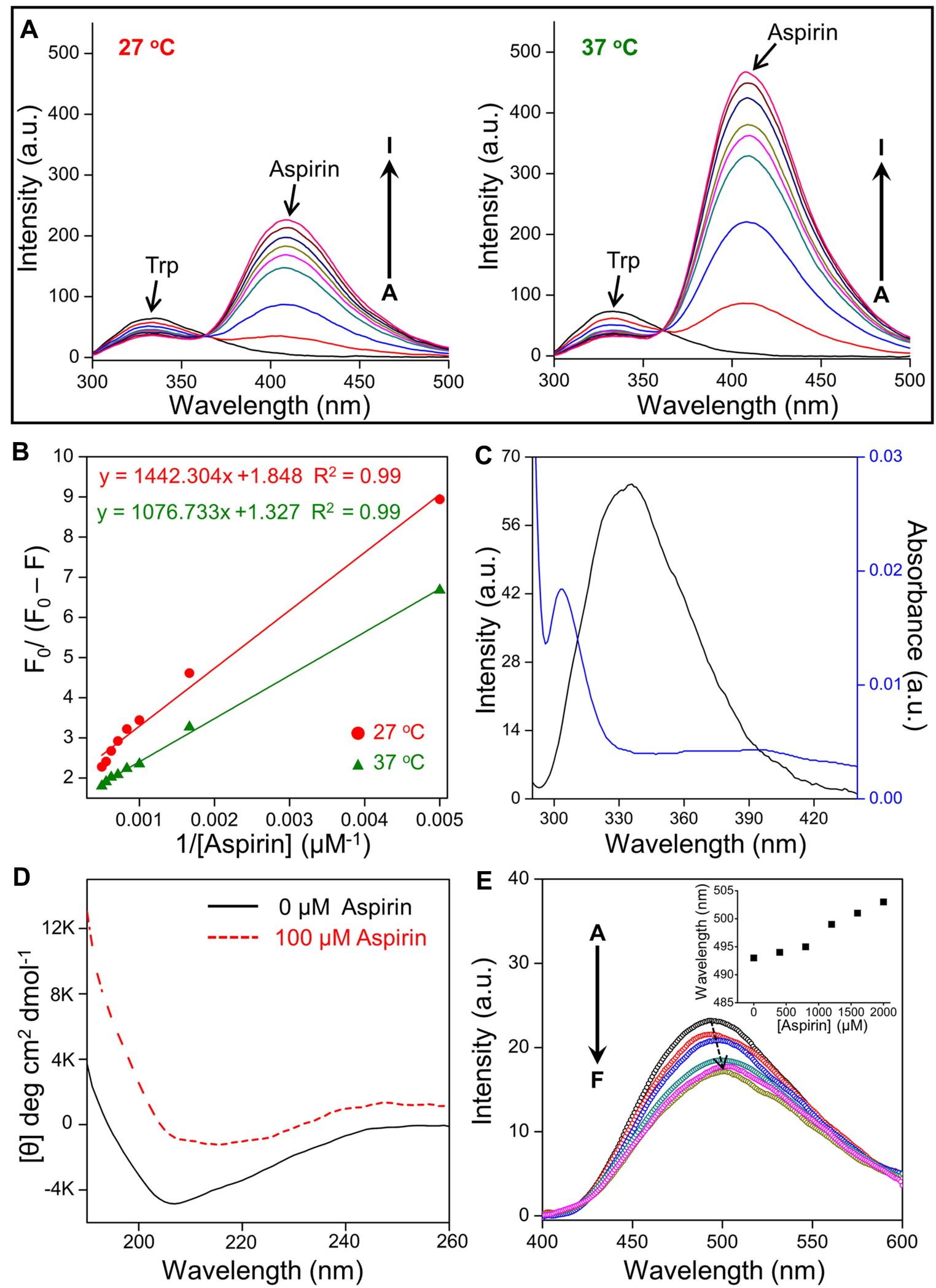

Figure I (A) Fluorescence emission spectra of BLG $(5 \mu \mathrm{M})$ in presence of different concentrations of aspirin $(A=0, B=200, C=600, D=1000, E=1200, F=1400, G=$ $1600, \mathrm{H}=1800$, and $\mathrm{I}=2000 \mu \mathrm{M})$. (B) Modified Stern-Volmer plots of BLG $(5 \mu \mathrm{M})$ interaction with different concentrations of aspirin. (C) Overlaps of the fluorescence emission spectra of BLG $(5 \mu \mathrm{M})$ and the UV-vis absorbance spectra of aspirin (1000 $\mu \mathrm{M})$. (D) Circular dichroism spectra of BLG (5 $\mu \mathrm{M})$ in the absence and presence of aspirin at $37^{\circ} \mathrm{C}$. (E) ANS emission of BLG $(5 \mu \mathrm{M})$ upon increasing concentrations of aspirin $(A=0, B=400, C=800, D=1200, E=1600$ and $\mathrm{F}=2000 \mu \mathrm{M})$ at $37^{\circ} \mathrm{C}$; the inset is the wavelength values of emission maxima. All solutions were prepared with $\mathrm{PBS}$ solution at $\mathrm{pH}=7.4$. 
Table I Modified Stern-Volmer Quenching Constants $\left(K_{s v}\right)$ and Bimolecular Quenching Rate Constant $\left(K_{q}\right)$ and of the Aspirin-BLG Complex at $\mathrm{pH}=7.4$

\begin{tabular}{|l|c|c|}
\hline Temp $\left({ }^{\circ} \mathrm{C}\right)$ & $K_{S V}\left(\times 10^{3} \mathrm{M}^{-1}\right)$ & $K_{q}\left(\times 10^{12} \mathrm{M}^{-1} \mathrm{~s}^{-1}\right)$ \\
\hline 27 & 1.281 & 1.001 \\
\hline 37 & 1.234 & 0.964 \\
\hline
\end{tabular}

be seen that, with increasing temperature, the values of $K_{b}$ and $n$ both increase obviously, suggesting that heating is beneficial to the formation of aspirin-BLG complex. Namely, the formation process should be an endothermic reaction. Basing on the obtained $K_{b}$ values, the Gibbs free energy $(\Delta G)$, enthalpy change $(\Delta H)$ and entropy change $(\Delta S)$ could be
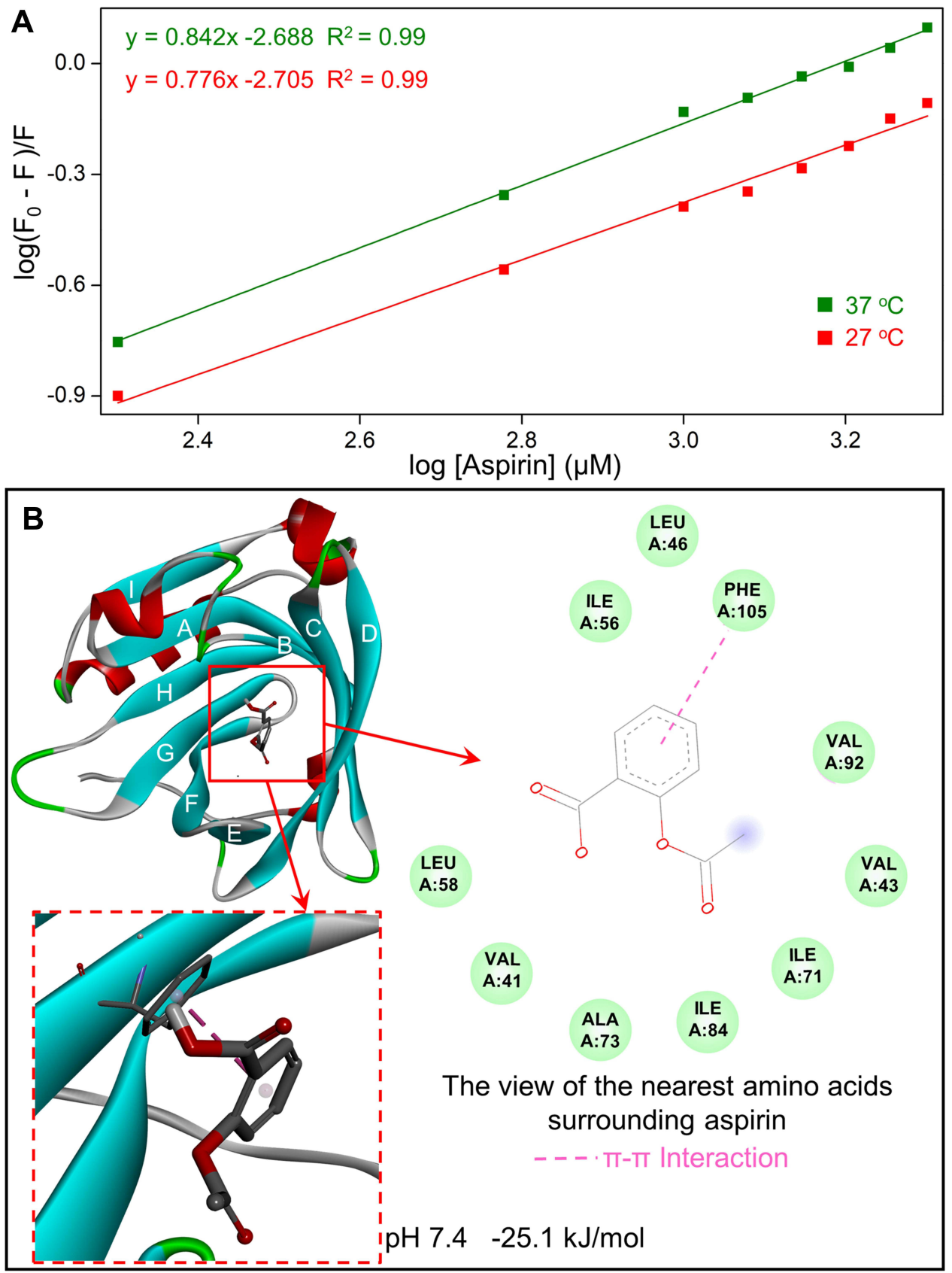

Figure $2(\mathbf{A})$ The curves of $\log \left[\left(F_{0}-\mathrm{F}\right) / \mathrm{F}\right]$ vs $\log [\mathrm{C}]$ of $\mathrm{BLG}$ interaction with aspirin at $\mathrm{pH}$ 7.4. (B) Molecular docking analysis of aspirin-BLG complex at $\mathrm{pH}$ 7.4. 
Table 2 Binding Parameters and Thermodynamic Parameters of the Aspirin-BLG Complex at $\mathrm{pH}=7.4$

\begin{tabular}{|c|c|c|c|c|c|}
\hline Temp $\left({ }^{\circ} \mathrm{C}\right)$ & $K_{b}\left(\times 10^{3} M^{-1}\right)$ & $n$ & $\Delta G\left(\mathbf{k J ~ \mathrm { mol } ^ { - 1 } )}\right.$ & $\Delta H\left(\mathrm{~kJ} \mathrm{~mol}{ }^{-1}\right)$ & $\Delta S\left(\mathrm{~J} \mathrm{~mol}^{-1}\right)$ \\
\hline 27 & 1.974 & 0.776 & -18.935 & \multirow[t]{2}{*}{2.958} & \multirow[t]{2}{*}{72.942} \\
\hline 37 & 2.051 & 0.842 & -19.664 & & \\
\hline
\end{tabular}

computed via van't Hoff equation (Eq. 7). ${ }^{52,53}$ These thermodynamic parameters are useful to predicate the main noncovalent forces stabilizing ligand-protein complex, including electrostatic interactions $(\Delta H<0$ and $\Delta S>0$ ); hydrophobic force $(\Delta H>0$ and $\Delta S>0)$; van der Waals force or hydrogen bonds $(\Delta H<0$ and $\Delta S<0) .{ }^{42,43,53}$ As listed in Table 2, the negative values of $\Delta G$ indicate that the formation process is spontaneous. Meanwhile, the positive $\Delta H$ and $\Delta S$ values reveal that the main acting force of aspirin-BLG complex is hydrophobic force.

To detail binding sites of aspirin-BLG complex, molecular docking was performed using AutoDock Vina and the obtained results were analyzed using Discovery Studio. For the aspirin-BLG complex under the condition of $\mathrm{pH}$ 7.4, the molecular docking was performed by approaching aspirin molecule to three binding sites reported in previous researches. ${ }^{23-25,44}$ The information of each site and corresponding free binding energy is listed in Table S3. Obviously, the central hydrophobic cavity of $\beta$-barrel should be the main site for binding aspirin, which yields the most energetically favorable conformation with a free binding energy of $-25.12 \mathrm{KJ} \mathrm{mol}^{-1}$. As shown in Figure $2 \mathrm{~B}$ and

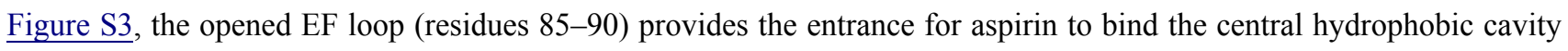
of $\beta$-barrel, causing the $\beta$-barrel to almost wrap the whole aspirin molecule. In this case, the aspirin molecule is surrounded by Ile-56, Leu-46, Phe-105, Val-92, Val-43, Ile-71, Ile-84, Ala-73, Val-41, Leu-58 residues, in which all amino acid residues are hydrophobic. This indicates that the hydrophobic force between these hydrophobic residues and aspirin, especially the $\pi-\pi$ interaction between the Phe-105 residue and aspirin (Figure 2B), might contribute to the stability of the aspirin-BLG complex, which is consistent with the results of ANS binding analysis (Figure 1E) and thermodynamic analyses (Figure 2A and Table 2). In addition, the molecular docking results also show the distance between aspirin and $\operatorname{Trp} 19$ is $1.07 \mathrm{~nm}$, which is quite close to the result obtained from FRET study $\left(\mathrm{r}_{0}=1.05 \mathrm{~nm}\right)$. For this tiny difference, it may be caused by differences in the BLG structure between in molecular docking analyses and in experiments studies. ${ }^{39,54}$ The molecular docking analyses are performed using the X-ray structure data from protein crystals, while the experiments studies were performed basing on the fact that the protein was dissolved in the aqueous medium.

\section{Stability of Aspirin-BLG Complex in Simulated Gastric Fluid}

From the viewpoint of oral administration of drugs, the drug solution would be diluted by gastric fluid after entering the stomach, causing its $\mathrm{pH}$ to be significantly reduced and even close to gastric fluid $(\mathrm{pH}=1 \sim 2)$. To mimic this condition, the aspirin-BLG complex in simulated gastric fluid was prepared by diluting the aspirin-BLG stock solution (previously prepared in PBS) into simulated gastric fluid. Then, its stability was evaluated by examining the quenching degree of fluorescence intensity (ie, the $F / F_{0}$ values). In parallel, the aspirin-BLG complex in PBS solution was used as a control group. As shown in Figure 3A, the $F / F_{0}$ value of each aspirin-BLG complex sample in simulated gastric fluid is evidently lower than that in PBS solution, indicating that the fluorescence quenching degree of each sample is obviously stronger in simulated gastric fluid. Moreover, Figure 3B clearly show that the $F / F_{0}$ value of each aspirin-BLG complex sample in simulated gastric fluid remains nearly constant even after the treatment time was extended to $9 \mathrm{~h}$, suggesting that these changes in fluorescence quenching degrees are relatively stable These results reveal that in simulated gastric fluid, BLG has a higher affinity for aspirin and aspirin is difficult to release from formed aspirin-BLG complex. Meanwhile the obtained aspirin-BLG complex is resistant to gastric digestion and relatively stable over several hours.

One of the main reasons for this interesting phenomenon may be the changes in binding mode and corresponding affinities of BLG for aspirin. To confirm this hypothesis, molecular docking was carried out and the protein structure of $\mathrm{BLG}$ at $\mathrm{pH}=2.0$ was chose as the representative of the BLG at $\mathrm{pH}$ values below $2.6 .{ }^{25,55}$ Figure $4 \mathrm{~A}$ and Figure $\mathrm{S} 4$ clearly 


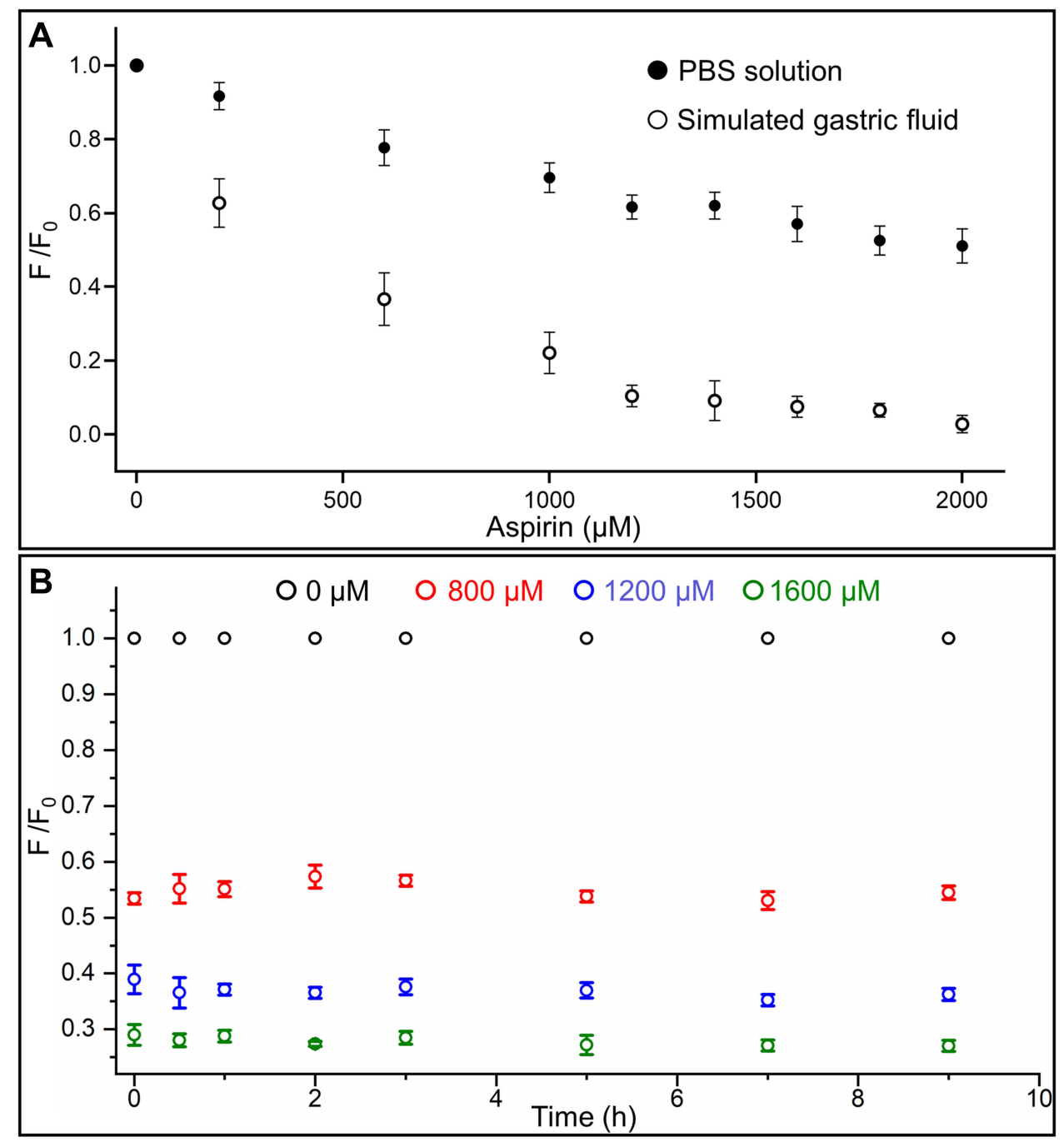

Figure $3(\mathbf{A})$ The $\mathrm{F} / \mathrm{F}_{0}$ values of BLG $(5 \mu \mathrm{M})$ interaction with different concentrations of aspirin in PBS solution and simulated gastric fluid at $37^{\circ} \mathrm{C}$ for 40 min. (B) The $\mathrm{F} / \mathrm{F}_{0}$ values of BLG $(10 \mu \mathrm{M})$ interaction with aspirin $(0,800,1200$ and $1600 \mu \mathrm{M})$ in simulated gastric fluid at $37^{\circ} \mathrm{C}$ for different times.

Notes: The results are expressed as the mean $\pm S D, n=3$.

display a new binding site on the surface of $\mathrm{BLG}$ at $\mathrm{pH}=2.0$, which is located on the external surface near the $\beta$-strand A and B. When binding to this newly formed site, the aspirin molecule is adjacent to Tyr-42, Phe-151, Leu-156, Trp-61, Gln-155, Gln-59, Gln-159, Cys-160, Glu-158 residues. The aspirin molecule has a $\pi$ - $\pi$ interaction with Tyr-42 residue and makes hydrogen bonds to Glu-158, Gln-59, Cys-160 residues. The free binding energy of aspirin to this site $(-29.3$ $\left.\mathrm{KJ} \mathrm{mol}^{-1}\right)$ at $\mathrm{pH} 2.0$ is obviously smaller than that of aspirin to the central hydrophobic cavity of $\beta$-barrel at $\mathrm{pH} 7.4$ $\left(-25.12 \mathrm{KJ} \mathrm{mol}^{-1}\right.$, shown in Figure 2B), meaning a more energetically favorable binding configuration of aspirin-BLG complex in simulated gastric fluid.

Besides the formation of a new binding site, safekeeping the originally bound aspirin molecule within the $\beta$-barrel might also be a potential cause. According to numerous researches, the EF loop can act as a gate over the $\beta$-barrel, which closes below $\mathrm{pH} 7.1$ and reversible opens at higher $\mathrm{pH}$ values. ${ }^{24,25,27}$ Therefore, when pre-preparing aspirin-BLG stock solution in PBS solution ( $\mathrm{pH}=7.4)$, the central hydrophobic cavity of $\beta$-barrel is the preferred binding site, resulting the aspirin molecules being "wrapped" in the $\beta$-barrel (Figure 2B and Figure S3). After diluting the aspirin-BLG stock solution into simulated gastric fluid $(\mathrm{pH}=1.2)$, the closed $\mathrm{EF}$ loop would theoretically seal off the $\beta$-barrel and safekeep the originally bound aspirin molecule. 

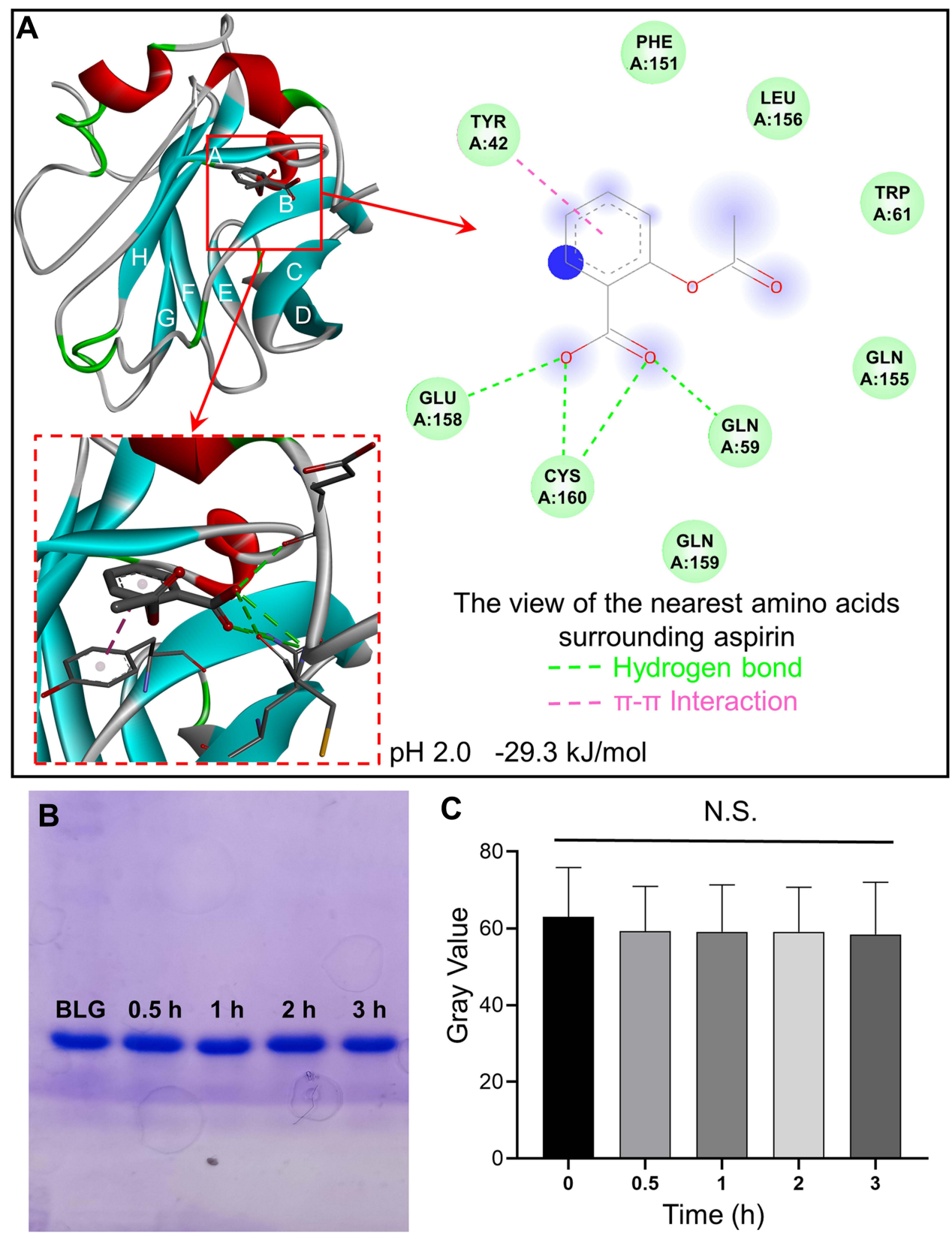

Figure 4 (A) Molecular docking analysis of aspirin-BLG complex at pH 2.0. (B) Representative SDS-PAGE patterns of samples obtained by digesting BLG in simulated gastric fluid for different times. (C) The gray values obtained from the SDS-PAGE patterns.

Notes: The results are expressed as the mean $\pm S D, n=3$. N.S. means no significant difference.

On the other hand, previous reports have shown that BLG is resistant to gastric digestion due to its acidic stability and can retain considerable integrity after passage through the stomach. ${ }^{24,35}$ To confirm this point, BLG was digested in simulated gastric fluid for different times and the obtained products were analyzed on 15\% SDS-PAGE. Figure 4B clearly displays that the main product after the digestion treatment is still BLG, and there is no visible low-molecular-weight product. Even after 3 hours of digestion, BLG is hard to be decomposed and almost completely maintained with negligible reduction (Figure 4C).

All above data strongly suggest that the special binding mode between BLG with aspirin in gastric fluid and the strong tolerance of BLG to gastric digestion are mainly responsible for the changes in fluorescence quenching degrees (Figure 3). Hence, this observation also leads to a hypothesis that BLG could act as a carrier to bind aspirin and reduce the damage effects of aspirin on the gastric mucosa. 


\section{Effects of Taking Aspirin-BLG on the Stomach}

To figure out the different effects between taking aspirin and taking aspirin-BLG on stomach, healthy Wistar rats were fed with a single dose of aspirin or aspirin-BLG solutions (10 $\mathrm{mL}$ per kilogram body weight, everyday). In parallel, the PBS solution was also used and the corresponding rats were considered as a control group. Figure S5 shows that during continuous oral administration, the body weight of rats in each group increased normally, and there is no significant difference among the three groups. After 14 days, the gastric tissue of each rat was isolated and observed. The stomachs from the rats of the PBS group display normal mucosa that are pink and without hemorrhages (Figure 5A), whereas the stomachs from the rats of the aspirin group exhibit obvious hemorrhagic streaks on the mucosal surface (black arrows in Figure 5B). Interestingly, the stomachs from the rats of the aspirin-BLG group are similar to those of PBS group (Figure 5C), which just show normal mucosa and without obvious hemorrhages. Thus, this indicates that the oral administration of aspirin-BLG might reduce the hemorrhages which often occurs after taking aspirin alone.

In addition, the sectioned glandular portions of stomachs from the rats were also stained with hematoxylin-eosin to further evaluate the gastric damage, and the corresponding results are shown in Figure 5D-F. The gastric mucosa samples from the rats of the PBS group display a normal histoarchitecture without epithelial disruption, deep damage, edema, or necrotic lesion (Figure 5D). Meanwhile, the gastric mucosa samples from the rats of the aspirin group are markedly disrupted and eroded, which even extend to the submucosa vicinity and lead to visible necrotic debris (Figure 5E). Nevertheless, the gastric mucosa samples from the rats of the aspirin-BLG group are similar to those of PBS group and show a relatively intact histoarchitecture, except that a small part of the mucosal surface epithelium is slightly shredded (black arrows in Figure 5F). The results of histological analyses suggest that the oral administration of aspirin-BLG cause less damage to gastric tissue (compared with the oral administration of aspirin), which is in line with the morphological observations results (Figure 5A-C).

Given that damaged gastric mucosa usually triggers immune responses, the occurrence of inflammation is usually considered as an important feature and indicator of aspirin-induced gastric injury. ${ }^{8,9}$ Thus, to further evaluate the degree of gastric damage, the gene expression levels of pro-inflammatory cytokines in gastric tissues were measured by qRTPCR, including tumor necrosis factor $\alpha$ (TNF- $\alpha$ ) and interleukin-1 $\beta$ (IL-1 $\beta){ }^{5,10}$ The corresponding results are shown in Figure 6. In comparison with the PBS group, the aspirin group shows markedly upregulations in the gene expression levels of these pro-inflammatory cytokines, suggesting that aspirin would cause damage to gastric tissue and trigger obvious inflammatory responses. However, the gene expression levels of these pro-inflammatory cytokines in the aspirinBLG group are significantly lower than those in the aspirin group, and only slightly higher than those in the PBS group
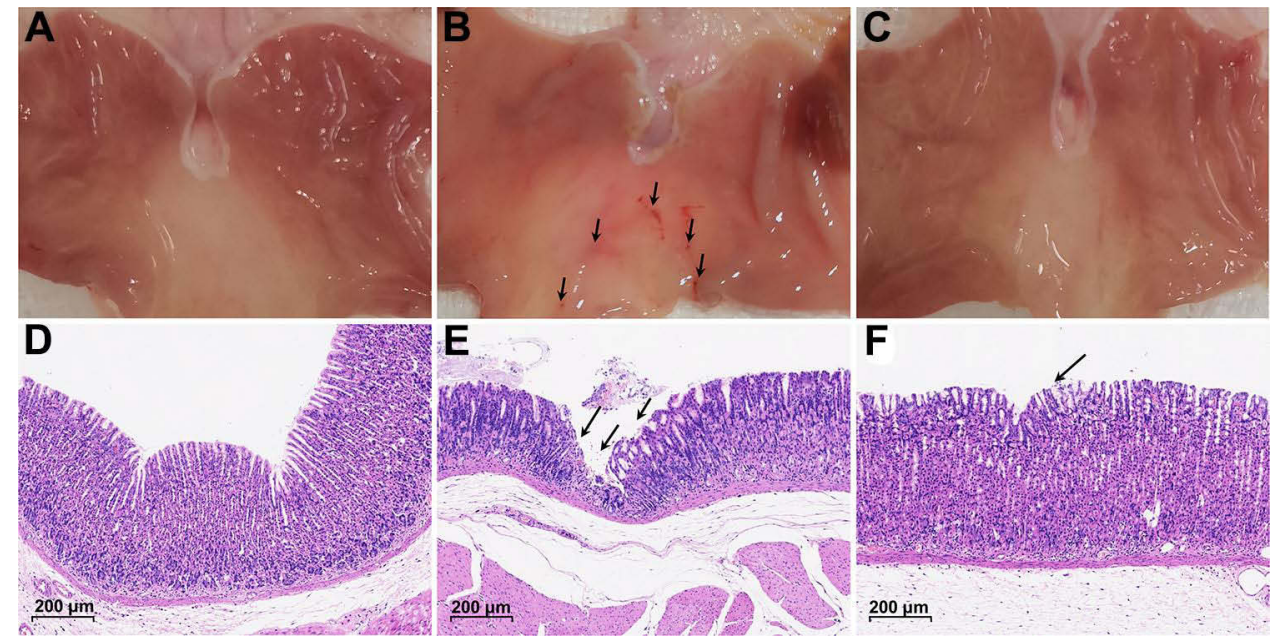

Figure 5 Representative morphological photographs of gastric tissues from the rats of different groups: (A) PBS group; (B) aspirin group, arrows indicate hemorrhagic streaks on the mucosal surface; (C) aspirin-BLG group. Representative hematoxylin-eosin staining images of gastric tissues from the rats of different groups: (D) PBS group; (E) aspirin group, arrows indicate disruption and erosion of gastric mucosa; $(\mathbf{F})$ aspirin-BLG group, arrows indicate slightly shredded mucosal surface epithelium. Notes: In (D), (E) and (F), scale bar $=200 \mu \mathrm{m}$. 
A

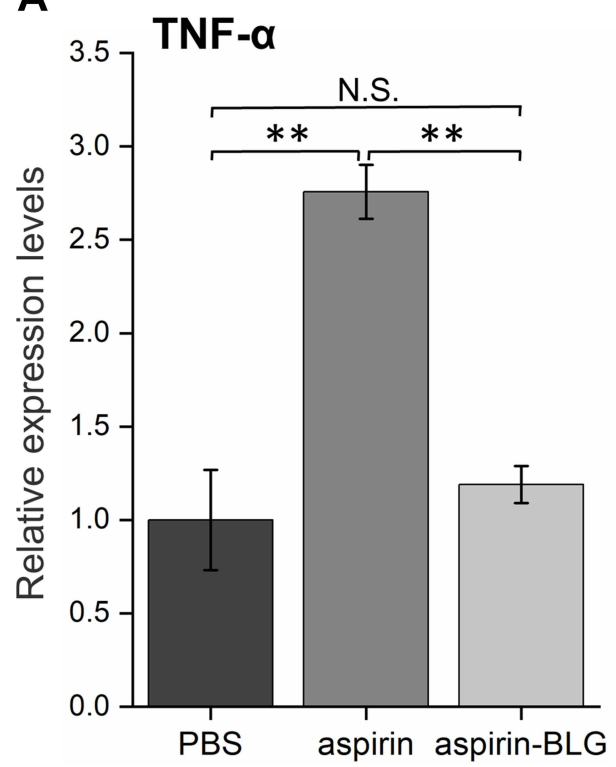

B

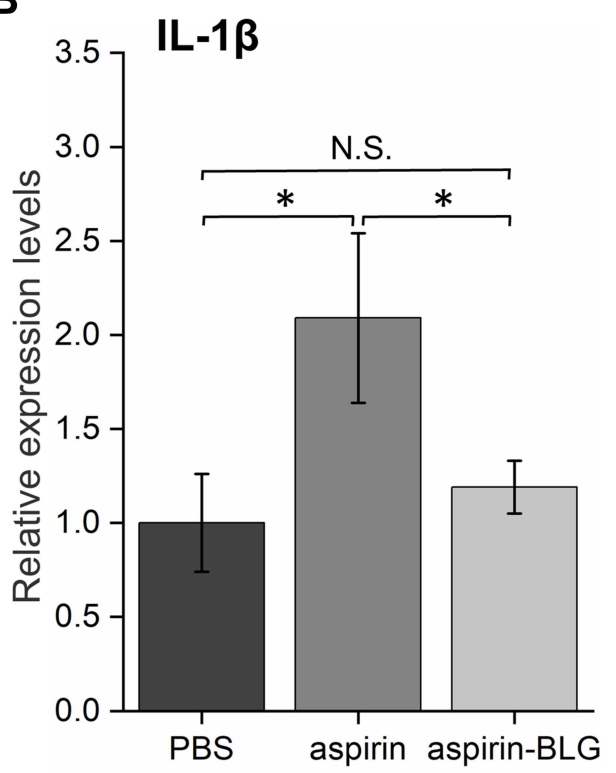

Figure 6 qRT-PCR analysis for the genes expression levels of pro-inflammatory cytokines in gastric tissues: (A) TNF- $\alpha$; (B) IL-I $\beta$.

Notes: The results are expressed as the mean $\pm S D, n=3$ biologically independent measurements, $* P<0.05$, **P $<0.0$ I, N.S. means no significant difference. Abbreviations: TNF- $\alpha$, tumor necrosis factor $\alpha$; IL-I $\beta$, interleukin-I $\beta$.

(without significant difference). The results manifest that taking aspirin-BLG would not cause significant damage to gastric mucosa, nor does it initiate obvious inflammatory response. In other words, the binding of aspirin to BLG could perform protective effects on gastric tissue.

\section{Conclusion}

In this work, we investigated the interaction between BLG and aspirin, and explored the role of BLG in alleviating aspirin-induced gastric injury. The results of various spectroscopic studies demonstrate that the interaction of BLG with aspirin leads to the formation of aspirin-BLG complex (the binding constant $K_{b}=2.051 \times 10^{3} \mathrm{M}^{-1}$ ) and the conformational changes in the structure of BLG, in which the predominant fluorescence quenching mechanism is a static quenching procedure (the quenching constant $K_{S V}=1.234 \times 10^{3} \mathrm{M}^{-1}$ ) and the main acting is hydrophobic force. The molecular docking results agree well with these experimental results and reveal that the central hydrophobic cavity of $\beta$-barrel is the major site to bind aspirin at $\mathrm{pH}$ 7.4. Our data also demonstrate that BLG has a higher affinity for aspirin in simulated gastric fluid and the obtained aspirin-BLG complex is relatively stable over several hours. One of the main reasons for this interesting phenomenon is the formation of a new and more stable binding site on the surface of BLG. On the other hand, the closed EF loop under acidic condition would theoretically seal off the $\beta$-barrel and safekeep the originally bound aspirin molecule. Meanwhile, the strong tolerance of BLG to gastric digestion also contributes to the good stability of aspirin-BLG in simulated gastric fluid. These findings would provide new insights into the interaction mechanism between BLG and aspirin.

Furthermore, based on these findings, we proposed a strategy to reduce the aspirin-induced gastric injury via using BLG to bind aspirin. This idea was verified by animal experiments. The results of morphology observations and histological analyses show that the oral administration of aspirin-BLG cause less damage to gastric tissue. Meanwhile, the qRT-PCR results manifest that taking aspirin-BLG rarely causes inflammatory responses in gastric tissue. Hence, our data reveal that the formation of aspirin-BLG complex could alleviate aspirin-induced gastric injury, which may be a new and feasible strategy to protect gastric tissue. Theoretically, this strategy should be able to cooperate with other strategies, such as co-administration of aspirin with other drugs, to further improve the clinical effect of aspirin. 


\section{Acknowledgments}

This work is supported by the National Natural Science Foundation of China $(32160226,31860262,32160224$ and 12132006), the China Postdoctoral Science Foundation (2019M653492), the Guizhou Provincial Natural Science Foundation ([2020]1Y091, [2018]5779-54, ZK[2021]029 and ZK[2021]436), the Guizhou Provincial Health Commission Science and Technology Foundation (gzwjkj2020-1-243 and gzwjkj2019-1-170), the Natural Science Foundation of Education Department of Guizhou Province (KY[2021]179 and KY[2021]159), and the Science Foundation of Guizhou Medical University ([2018]Z01 and 20NSP056).

\section{Disclosure}

The authors have no conflicts of interest for this work to declare.

\section{References}

1. Desborough MJR, Keeling DM. The aspirin story-from willow to wonder drug. Br J Haematol. 2017;177(5):674-683. doi:10.1111/bjh.14520

2. Schrör K, Voelker M. NSAIDS and Aspirin: Recent Advances and Implications for Clinical Management. Lanas A ed. Springer International Publishing; 2016.

3. Ricciotti E, Fitzgerald GA. Aspirin in the prevention of cardiovascular disease and cancer. Annu Rev Med. 2021;72(1):473-495. doi:10.1146/ annurev-med-051019-102940

4. Thun MJ, Jacobs EJ, Patrono C. The role of aspirin in cancer prevention. Nat Rev Clin Oncol. 2012;9(5):259-267. doi:10.1038/nrclinonc.2011.199

5. Kalathil AA, Kumar A, Banik B, Ruiter TA, Pathak RK, Dhar S. New formulation of old aspirin for better delivery. Chem Commun (Camb). 2016;52(1):140-143. doi:10.1039/c5cc07316b

6. Lanas A, Scheiman J. Low-dose aspirin and upper gastrointestinal damage: epidemiology, prevention and treatment. Curr Med Res Opin. 2007;23 (1):163-173. doi:10.1185/030079907X162656

7. Handa O, Naito Y, Fukui A, Omatsu T, Yoshikawa T. The impact of non-steroidal anti-inflammatory drugs on the small intestinal epithelium. J Clin Biochem Nutr. 2014;54(1):2-6. doi:10.3164/jcbn.13-84

8. Matsui H, Shimokawa O, Kaneko T, Nagano Y, Rai K, Hyodo I. The pathophysiology of non-steroidal anti-inflammatory drug (NSAID)-induced mucosal injuries in stomach and small intestine. J Clin Biochem Nutr. 2011;48(2):107-111. doi:10.3164/jcbn.10-79

9. Basson MD. Hierarchies of healing in gut mucosal injury. J Physiol Pharmacol. 2017;68(6):789-795.

10. Odashima M, Otaka M. Rolipram, a specific type IV phosphodiesterase inhibitor, ameliorates aspirin-induced gastric mucosal injury in rats. Dig Dis Sci. 2005;50(6):1097-1102. doi:10.1007/s10620-005-2711-9

11. Ammar HO, Ghorab M, El-Nahhas SA, Kamel R. Design of a transdermal delivery system for aspirin as an antithrombotic drug. Int $J$ Pharm. 2006;327(1-2):81-88. doi:10.1016/j.ijpharm.2006.07.054

12. Rolla G, Di Emanuele A, Dutto L, et al. Effect of inhalation aspirin challenge on exhaled nitric oxide in patients with aspirin-inducible asthma. Allergy. 2004;59(8):827-832. doi:10.1111/j.1398-9995.2004.00502.x

13. Mahmoud YI, Abd El-Ghffar EA. Spirulina ameliorates aspirin-induced gastric ulcer in albino mice by alleviating oxidative stress and inflammation. Biomed Pharmacother. 2019;109:314-321. doi:10.1016/j.biopha.2018.10.118

14. Adefisayo MA, Akomolafe RO, Akinsomisoye SO, et al. Gastro-protective effect of methanol extract of Vernonia amygdalina (del.) leaf on aspirin-induced gastric ulcer in Wistar rats. Toxicol Rep. 2017;4:625-633. doi:10.1016/j.toxrep.2017.11.004

15. Ahadian S, Finbloom JA, Mofidfar M, et al. Micro and nanoscale technologies in oral drug delivery. Adv Drug Deliv Rev. 2020;157:37-62. doi:10.1016/j.addr.2020.07.012

16. Abbaraju PL, Meka AK, Jambhrunkar S, et al. Floating tablets from mesoporous silica nanoparticles. J Mater Chem B. 2014;2(47):8298-8302. doi:10.1039/c4tb01337a

17. Wang PP, Luo ZG, Tamer TM. Spiral-Dextrin Complex Crystals: efficient Approach for Colon-Targeted Resveratrol Delivery. J Agric Food Chem. 2021;69(1):474-482. doi:10.1021/acs.jafc.0c05668

18. Li S, Wang K, Zong M, et al. Preparation and evaluation of nano-hydroxyapatite/poly (styrene-divinylbenzene) porous microsphere for aspirin carrier. Sci China Chem. 2012;55:1134-1139. doi:10.1007/s11426-012-4519-8

19. Li X, Yang Q, Ouyang J, Yang H, Chang S. Chitosan modified halloysite nanotubes as emerging porous microspheres for drug carrier. Appl Clay Sci. 2016;126:306-312. doi:10.1016/j.clay.2016.03.035

20. Lu H, Ouyang J, Yang H. Natural halloysite nanotubes modified as an aspirin carrier. RSC Adv. 2014;4:44197-44202. doi:10.1039/c4ra09006c

21. Zhang Q, Zhu Z, Ni Y. Interaction between aspirin and vitamin C with human serum albumin as binary and ternary systems. Spectrochim Acta a Mol Biomol Spectrosc. 2020;236:118356. doi:10.1016/j.saa.2020.118356

22. Nafisi S, Sadeghi GB, PanahYab A. Interaction of aspirin and vitamin C with bovine serum albumin. J Photochem Photobiol B. 2011;105 (3):198-202. doi:10.1016/j.jphotobiol.2011.09.002

23. Kontopidis G, Holt C, Sawyer L. Invited review: $\beta$-lactoglobulin: binding properties, structure, and function. J Dairy Sci. 2004;87(4):785-796. doi:10.3168/jds.S0022-0302(04)73222-1

24. Maux SL, Bouhallab S, Giblin L, Brodkorb A, Croguennec T. Bovine $\beta$-lactoglobulin/fatty acid complexes: binding, structural, and biological properties. Dairy Sci Technol. 2014;94(5):409-426. doi:10.1007/s13594-014-0160-y

25. Bello M, García-Hernández E. Ligand entry into the calyx of $\beta$-lactoglobulin. Biopolymers. 2014;101(7):744-757. doi:10.1002/bip.22454

26. Al-Shabib NA, Khan JM, Malik A, et al. Molecular interaction of tea catechin with bovine $\beta$-lactoglobulin: a spectroscopic and in silico studies. Saudi Pharm J. 2020;28(3):238-245. doi:10.1016/j.jsps.2020.01.002

27. Wang Y, Gong M, Huang Z, et al. Spectroscopic and theoretical investigation of $\beta$-Lactoglobulin interactions with hematoporphyrin and protoporphyrin IX. ACS Omega. 2021;6(14):9680-9691. doi:10.1021/acsomega.1c00279 
28. Waghmare MN, Qureshi TS, Krishna CM, et al. $\beta$-Lactoglobulin-gold nanoparticles interface and its interaction with some anticancer drugs - an approach for targeted drug delivery. J Biomol Struct Dyn. 2021:1-25. doi:10.1080/07391102.2021.1879270

29. Izadi Z, Divsalar A, Saboury AA, Sawyer L. $\beta$-lactoglobulin-pectin Nanoparticle-based Oral Drug Delivery System for Potential Treatment of Colon Cancer. Chem Biol Drug Des. 2016;88(2):209-216. doi:10.1111/cbdd.12748

30. Pujara N, Wong KY, Qu Z, et al. Oral Delivery of $\beta$-Lactoglobulin-Nanosphere-Encapsulated Resveratrol Alleviates Inflammation in Winnie Mice with Spontaneous Ulcerative Colitis. Mol Pharm. 2021;18(2):627-640. doi:10.1021/acs.molpharmaceut.0c00048

31. Sahihi M, Ghayeb Y. Binding of biguanides to $\beta$-lactoglobulin: molecular-docking and molecular dynamics simulation studies. Chemical Papers. 2014;6:1601-1607. doi:10.2478/s11696-014-0598-7

32. Mohammadi F, Sahihi M, Bordbar AK. Multispectroscopic and molecular modeling studies on the interaction of two curcuminoids with $\beta$ lactoglobulin. Spectrochim Acta a Mol Biomol Spectrosc. 2015;140:274-282. doi:10.1016/j.saa.2014.12.032

33. Chavoshpour-Natanzia Z, Sahihi M. Encapsulation of quercetin-loaded $\beta$-lactoglobulin for drug delivery using modified anti-solvent method. Food Hydrocoll. 2019;96:493-502. doi:10.1016/j.foodhyd.2019.05.051

34. Schiefner A, Skerra A. The menagerie of human lipocalins: a natural protein scaffold for molecular recognition of physiological compounds. Acc Chem Res. 2015;48(4):976-985. doi:10.1021/ar5003973

35. Shafaei Z, Ghalandari B, Vaseghi A, et al. $\beta$-Lactoglobulin: an efficient nanocarrier for advanced delivery systems. Nanomedicine. 2017;13 (5):1685-1692. doi:10.1016/j.nano.2017.03.007

36. Pujara N, Giri R, Wong KY, et al. pH - Responsive colloidal carriers assembled from $\beta$-lactoglobulin and Epsilon poly-L-lysine for oral drug delivery. J Colloid Interface Sci. 2021;589:45-55. doi:10.1016/j.jcis.2020.12.054

37. Zhu J, Li K, Wu H, Li W, Sun Q. Multi-spectroscopic, conformational, and computational atomic-level insights into the interaction of $\beta$ lactoglobulin with apigenin at different pH levels. Food Hydrocoll. 2020;105:105810. doi:10.1016/j.foodhyd.2020.105810

38. Shahraki S, Shiri F, Heidari Majd M, Dahmardeh S. Anti-cancer study and whey protein complexation of new lanthanum(III) complex with the aim of achieving bioactive anticancer metal-based drugs. J Biomol Struct Dyn. 2019;37(8):2072-2085. doi:10.1080/07391102.2018.1476266

39. Ghalandari B, Divsalar A, Eslami-Moghadam M, et al. Probing of the interaction between $\beta$-Lactoglobulin and the anticancer drug oxaliplatin. Appl Biochem Biotechnol. 2014;175(2):974-987. doi:10.1007/s12010-014-1341-0

40. Ghalandari B, Divsalar A, Saboury AA, et al. Spectroscopic and theoretical investigation of oxali-palladium interactions with $\beta$-lactoglobulin Spectrochim Acta a Mol Biomol Spectrosc. 2014;118:1038-1046. doi:10.1016/j.saa.2013.09.126

41. Hemmateenejad B, Shamsipur M, Samari F, Khayamian T, Ebrahimi M, Rezaei Z. Combined fluorescence spectroscopy and molecular modeling studies on the interaction between harmalol and human serum albumin. J Pharm Biomed Anal. 2012;67-68:201-208. doi:10.1016/j. jpba.2012.04.012

42. Yang L, Huo D, Hou C, Yang M, Fa H, Luo X. Interaction of monosulfonate tetraphenyl porphyrin (H2TPPS 1) with plant-esterase: determination of the binding mechanism by spectroscopic methods. Spectrochim Acta a Mol Biomol Spectrosc. 2011;78(5):1349-1355. doi:10.1016/j. saa.2011.01.009

43. Paul BK, Ghosh N, Mukherjee S. Binding interaction of a prospective chemotherapeutic antibacterial drug with $\beta$-lactoglobulin: results and challenges. Langmuir. 2014;30(20):5921-5929. doi:10.1021/la501252x

44. Liang L, Subirade M. $\beta$-lactoglobulin/folic acid complexes: formation, characterization, and biological implication. J Phys Chem B. 2010;114 (19):6707-6712. doi:10.1021/jp101096r

45. Wang C, Zhou X, Wang H, Sun X, Guo M. Interactions between $\beta$-lactoglobulin and 3,3`-diindolylmethane in model system. Molecules. $2019 ; 24$ (11):2151. doi:10.3390/molecules24112151

46. Roufegarinejad L, Amarowicz R, Jahanban-Esfahlan A. Characterizing the interaction between pyrogallol and human serum albumin by spectroscopic and molecular docking methods. J Biomol Struct Dyn. 2019;37(11):2766-2775. doi:10.1080/07391102.2018.1496854

47. Zimet P, Livney YD. $\beta$-lactoglobulin and its nanocomplexes with pectin as vehicles for $\omega-3$ polyunsaturated fatty acids. Food Hydrocoll. $2009 ; 23$ (4):1120-1126. doi:10.1016/j.foodhyd.2008.10.008

48. Sharma A, Ghosh KS. Studies on molecular interactions between bovine $\beta$-lactoglobulin and silver nanoparticles. Protein Pept Lett. 2020;27 (8):793-800. doi:10.2174/0929866527666200129123018

49. Chen T, Zhu X, Chen Q, et al. Interaction between z-ligustilide from radix angelica sinensis and human serum albumin. Food Chem. 2015;186:292-297. doi:10.1016/j.foodchem.2014.11.041

50. Rabbani G, Baig MH, Jan AT, et al. Binding of erucic acid with human serum albumin using a spectroscopic and molecular docking study. Int J Biol Macromol. 2017;105(pt 3):1572-1580. doi:10.1016/j.ijbiomac.2017.04.051

51. Jayabharathi J, Thanikachalam V, Srinivasan N, Perumal MV. Luminescent study on the binding interaction of bioactive imidazole with bovine serum albumin-A static quenching mechanism. Spectrochim Acta a Mol Biomol Spectrosc. 2011;84(1):233-237. doi:10.1016/j.saa.2011.09.033

52. Roufegarinejad L, Jahanban-Esfahlan A, Sajed-Amin S, Panahi-Azar V, Tabibiazar M. Molecular interactions of thymol with bovine serum albumin: spectroscopic and molecular docking studies. J Mol Recognit. 2018;31(7):2704. doi:10.1002/jmr.2704

53. Jahanban-Esfahlan A, Panahi-Azar V, Sajedi S. Interaction of glutathione with bovine serum albumin: spectroscopy and molecular docking. Food Chem. 2016;202:426-431. doi:10.1016/j.foodchem.2016.02.026

54. Yue Y, Chen X, Qin J, Yao X. Spectroscopic investigation on the binding of antineoplastic drug oxaliplatin to human serum albumin and molecular modeling. Colloids Surf B Biointerfaces. 2009;69(1):51-57. doi:10.1016/j.colsurfb.2008.10.016

55. Uhrínová S, Smith MH, Jameson GB, Uhrín D, Sawyer L, Barlow PN. Structural changes accompanying pH-induced dissociation of the $\beta$ lactoglobulin dimer. Biochemistry. 2000;39(13):3565-3574. doi:10.1021/bi992629o 


\section{Publish your work in this journal}

Drug Design, Development and Therapy is an international, peer-reviewed open-access journal that spans the spectrum of drug design and development through to clinical applications. Clinical outcomes, patient safety, and programs for the development and effective, safe, and sustained use of medicines are a feature of the journal, which has also been accepted for indexing on PubMed Central. The manuscript management system is completely online and includes a very quick and fair peer-review system, which is all easy to use. Visit http://www.dovepress.com/testimonials.php to read real quotes from published authors.

Submit your manuscript here: https://www.dovepress.com/drug-design-development-and-therapy-journal 